\title{
A Novel Fixed Column Bed Device for Removal of Polycyclic Aromatic Hydrocarbon (Pyrene) from Water: Performance Evaluation and Thermodynamic Modelling
}

\author{
Anusha D.L. Wickramasinghe ${ }^{1,2}$, S.P. Shukla ${ }^{1 *}$, A.K. Balange ${ }^{3}$, \\ K. Pani Prasad ${ }^{1}$ and Sanath Kumar ${ }^{3}$ \\ ${ }^{1}$ Aquatic Environment and Health Management Division, ICAR-Central Institute of Fisheries \\ Education, Mumbai, Maharashtra, India \\ ${ }^{2}$ Faculty of Fisheries and Ocean Sciences, Ocean University of Sri Lanka, Sri Lanka \\ ${ }^{3}$ Fisheries Resources Harvest \& Post-Harvest Division, ICAR-Central Institute of Fisheries \\ Education, Mumbai, Maharashtra, India \\ *Corresponding author
}

\section{A B S T R A C T}

\begin{tabular}{|c|}
\hline Keywords \\
\hline $\begin{array}{l}\text { Pyrene, Coconut coir, } \\
\text { Zeolite, Chitosan, Alginic } \\
\text { acid, Adsorption, Column } \\
\text { bed, Thermodynamic } \\
\text { modelling }\end{array}$ \\
\hline Article Info \\
\hline $\begin{array}{l}\text { Accepted: } \\
\text { 04 February } 2018 \\
\text { Available Online: } \\
10 \text { March } 2018\end{array}$ \\
\hline
\end{tabular}
(Zhang, 2013). PAHs are emitted through the

\section{Introduction}

Polycyclic aromatic hydrocarbons (PAHs) are pervasive environmental pollutants produced mainly by the incomplete combustion of organic materials such as coal, oil, petrol, wood, etc. (Abdel-Shafy and Mansour, 2015).

They are composed of fused benzene rings from natural as well as anthropogenic sources
Performance of a column bed device packed with specially fabricated Plaster of Paris (POP) pellets was evaluated for the removal of a potentially toxic Polycyclic Aromatic Hydrocarbon (PAH) Pyrene (Pyr). The effect of initial Pyr concentration, flow rate, and adsorbent dosage was investigated on Pyr adsorption characteristics of two types of pellets (uncoated and adsorbent coated). Maximum Bed capacity (Mb), percentage removal and equilibrium Pyr uptake were calculated and breakthrough curves were plotted. Data from column studies were fitted to three well-established column kinetic models; Thomas, Adams-Bohart, and Yoon-Nelson. The data were in good agreement with theoretical results. The study revealed the efficacy of newly designed pellets coated with thin layer of chitosan and alginic acid in the fixed bed column device for removal of Pyr from the water. Overall, the study provides a novel design of a column bed and baseline information for the efficient removal of PAH from the water. burning of fossil fuels or vegetation, natural losses or seepage of petroleum or coal deposits, and volcanic activities (Phillips, 1999). However, PAHs emissions mainly originate from anthropogenic activities such as residential heating, coal gasification and liquefying plants, carbon black, coal-tar pitch and asphalt production, coke and aluminum production, catalytic cracking towers and related activities in petroleum refineries as well as any motor vehicle exhaust. 
Most PAHs have toxic, mutagenic and carcinogenic (Abdel-Shafy and Mansour, 2015) and teratogenic (Zedeck, 1980). PAHs are readily absorbed from the gastrointestinal tract of mammals as they are highly lipid soluble and they distribute rapidly in a wide range of tissues with a noticeable tendency for localization in body fat (Abdel-Shafy and Mansour, 2015). Possible long-term health effects caused by exposure to PAHs include cataracts, kidney and liver damage and jaundice. There are several hundred different PAHs combinations, wherein up to16 compounds including Pyrene, have been identified as most hazardous contaminants by the U.S. Environmental Protection Agency (USEPA, 1992).Though some bacteria can mineralize Pyrene, it is also transformed to non-mineral products by a variety of other PAH-degrading bacteria (Kazunga and Aitken, 2000). Because of the adverse effects of PAHs on human health and environment, extensive studies on various types of PAHs removal methods like nano-filtration (Simons, 1993), membrane filtration (Ndiaye et al., 2005), ion-exchange (Ruixia et al., 2002), precipitation (Parthasarathy et al., 1986), electrochemical coagulation (Hu et al., 2005) and adsorption (Mohapatra et al., 2004) have been accomplished during past. Among them, the adsorption technique is quite promising because of the simplicity and the availability of many adsorbents from the natural environment. Also, adsorption is an effective and attractive process for removal of nonbiodegradable pollutants (including PAHs) from water (Aksu, 2005). As PAHs exhibit, a great sorptive ability their low aqueous solubility, sorption is considered as one of the widely used treatment methods (Lamichhane et al., 2016).

Several adsorbent media such as activated carbon, biochar, modified clay minerals have been widely used to remove PAHs from aqueous solution, and very high removal efficiency could be achieved using these adsorbents. However, due to their high cost especially in developing countries, the applicability is limited hence, preferably lowcost adsorbents such as industrial waste, natural material, or agricultural by-products are potential materials for PAH removal which do not require any expensive additional pretreatment step. And these natural adsorbent materials do not pose any risk to public health and environment, and therefore, can be disposed-off without any subjecting to any treatment process.

Most studies given testing the PAH removal capability have been conducted only in batch mode where the adsorbent is added to the metal solution for the sequestration of PAH molecules, which is not a practically feasible approach. But in column mode, removal mainly depends upon the creation of a larger surface/volume ratio of adsorbents by forming a uniformly thin layer in the interstitial space in the matrix. This curtails the quantity of adsorbents as required in batch mode, to a considerable extent, and makes desorption of PAHs and regeneration of column material less cumbersome.

Given the above, there is a growing interest among scientists to explore the novel technologies for low-cost column bed based treatment processes for PAHs remediation. Entrapment of biomass in a matrix or pellets have following advantages over suspended biosorbents (i) the particle size of the biosorbents can be effectively controlled (ii) biomass can be easily separated from the effluent after the treatment cycles (iii) the possibility of clogging under continuous flow conditions is minimized.

In addition to above, the easy method of biosorption-desorption makes the column based bio-sorption process more cost-effective than batch mode treatments. 
The successful design of a column adsorption process requires prediction of the concentration-time profile or breakthrough curve for the effluent and the maximum adsorption capacity of an adsorbent under given a set of operating conditions. Therefore, testing the fitness of column experimental data with commonly used kinetic models is important for prediction of column behaviour.

In the backdrop of the above, present study aimed to design a low-cost column based water filtration device with high reusability. A pelleted form of the adsorbent with a thin coating of adsorbent (a homogeneous mixture of Chitosan and Alginic acid) was fabricated using low-cost materials (Plaster of Paris, Zeolite) and agro waste (coconut coir) for removal of a potentially toxic PAH - Pyrene.

\section{Materials and Methods}

\section{Test chemical}

Pyrene was purchased from Supelco, SigmaAldrich (USA). The stock solution of Pyr was prepared freshly by dissolving a known quantity of Pyr in known but least amount of HPLC grade n-hexane purchased from Merck, India before starting the experiment.

\section{Other materials and glassware}

All the reagents and glassware used for the estimation of Pyr and removal experiments were of analytical grade with high purity procured from Merck, India. Anhydrous sodium sulfate of molecular grade together with Chitosan and Alginic acid, used for physical entrapment, was procured from Himedia, India. Plaster of Paris, Zeolite, Coconut coir sheet and polyurethane foam were procured from the local market of Mumbai (India). Deionized water was produced in a Milli-Q system (Millipore, France).

\section{Preparation of adsorbent coated pellets}

Pellets were made by using agro waste materials such as coconut coir (CC) and zeolite (Z) using Plaster of Paris as (POP) binding material. Coir was initially washed properly followed by dried under proper sunlight to evaporate all the water and to disinfect under natural UV with least cleaning cost. Cleaned coir was then cut into tiny pieces (around $2 \mathrm{~mm}$ ). Cut $\mathrm{CC}$ was mixed with $\mathrm{PP}$, and $\mathrm{Z}$ in the optimized ratio (unpublished data) in a clean container. This freshly prepared homogenized mixture was immediately added to the simply designed mold using disposable low-cost materials and spread evenly over the mold while tightening the mixture properly in the mold. The structure was left for air drying around 20 minutes followed by removal from the mold. The prepared pellets were left for further air drying followed by drying at $120^{\circ} \mathrm{C}$ in a hotair oven. The mixture of adsorbent (1\% $\mathrm{CS}+2 \% \mathrm{AA})$ was prepared and filtered to get the homogenized medium. The pellets were then immersed fully in the solution and dried at $55^{\circ} \mathrm{C}$ in an oven for 12 hours. Both coated and uncoated pellets were stored at room $\left(26 \pm 2^{\circ} \mathrm{C}\right)$ temperature in a desiccator.

\section{Designing of fixed bed column filtration unit}

The filtration unit used for the present study was designed by using low cost and locally available materials like polyurethane foam (PU), PVC pipes, and plastic containers. This was divided into two compartments and a column consisting of pellets. The column was placed at the junction of both the compartment with a vertical orientation. The upper part of the column (with 6.5 inches' diameter with 1inch thickness two PU discs and adsorbent pellets) was in contact with untreated PAH solution kept in upper compartment (Teflon bottle; 20L), and the lower portion of the 
column was placed over the lower compartment (Teflon container; 8L) and the treated water was discharged into the lower compartment after passing through the column.

\section{Experiment}

Pyrene solution of 201 volume, for every experiment, was filled in the upper compartment and experiments were carried out for two $\mathrm{h}$ and samples were collected at every $15 \mathrm{~min}$ interval in plastic bottles. Experiments were conducted at four different concentrations of Pyrviz. 0.01, 0.1, 1, and 10 $\mathrm{mg}^{-1}$ to test the effect of initial Pyr concentration on adsorption by pellets in the column. Also, the experiments of two different adsorbent doses, $220 \mathrm{~g}(8 \mathrm{~cm}), 440 \mathrm{~g}(16 \mathrm{~cm})$ were operated at same influent $\mathrm{Pyr}$ concentration $\left(10 \mathrm{mg} \mathrm{l}^{-1}\right)$ and flow rate (120 $\mathrm{ml} \mathrm{min}{ }^{-1}$ ) given studying the dose effect. For understanding the flow rate effect of $\mathrm{Pyr}$ adsorption, two flow rates were tested, 90 and $120 \mathrm{ml} \mathrm{m^{-1 }}$ under same Pyr initial concentration (10 $\left.\mathrm{mg} \mathrm{l}^{-1}\right)$ and bed depth (16 $\mathrm{cm})$. All these tests conducted in two sets using two types of pellets; uncoated and coated with bioadsorbents viz. chitosan (CS) and Alginic acid (AA).The quantity of adsorbent coated on a pellet was $36.5 \pm 0.02$ $\mathrm{mg}$. The final dry weight of coating layer was calculated through the dry weight difference of pellets before and after coating. An aqueous solution of Pyr in deionized water was passed through the column for $120 \mathrm{~min}$, and the effluent was collected at a regular interval of $15,30,45,60,75,90,105$ and 120 minutes.

The Pyr in the effluent solution was then extracted into n-hexane using the separatory funnel method described in "Marpolmon-P; manuals and guides no.13 published by Intergovernmental Oceanographic Commission (1984). The extract was concentrated by a rotary evaporator (Superfit,
India) up to $5 \mathrm{~mL}$ under reduced pressure (0.06-0.07 $\mathrm{MPa})$ at $450 \mathrm{C}$ in the water bath and $50 \mathrm{C}$. The concentrated fraction containing $\mathrm{Pyr}$ was analyzed in three replicates by GC/MS (Model QP2010, Shimadzu, Japan), operating in electron impact ionization mode $(70 \mathrm{eV})$. Compound separation was achieved using the column named Rxi®-5Sil MS column (fused silica; $5 \%$ phenyl, $95 \%$ dimethyl polysiloxane) of 30 $\mathrm{m}$ length $\times 0.25 \mathrm{~mm}$ i.d. with $0.25-\mu \mathrm{m}$ film thickness. The identification and quantification of analytes were carried out with Labsolutions - GC/MS Solution, (Release 2.30) software (Shimadzu, Japan).Verification of peaks was carried out based on retention times compared to those of external PAHs standards. The concentration of Pyrene was estimated using the EPA 610 (1984) method. Initial and final $\mathrm{pH}$ (after two-hour experiment) was measured. Room temperature was recorded during the experiment.

\section{Mathematical description}

The performance of the fixed-bed column (for a given flow rate, feed concentration, bed height and adsorbent dosage) was described through the maximum bed capacity, equilibrium PAH uptake, the total percentage of PAH removal and concept of the breakthrough curve.

\section{The effluent volume $\left(\boldsymbol{V}_{\text {eff }}\right)$}

$V_{\text {eff }}$ was calculated using the following equation:

$$
V_{\text {eff }}=Q t_{\text {total }}(1)
$$

Where, ${ }^{V_{\text {eff }}}$ is effluent volume collected, ml; $Q_{\text {is volumetric flow rate, }} \mathrm{ml} \mathrm{min}^{-1}$; $t_{\text {total }}$ is total flow time, min. 
The maximum bed capacity ${ }^{(\mathrm{Mb})}$

$\mathrm{Mb}$ for a given flow rate and feed concentration is calculated by the following equation:

$M b=\Sigma\left[\left(\mathrm{C}_{\mathrm{o}}-\mathrm{C}_{\mathrm{t}}\right) \times \mathrm{V}_{\mathrm{t}}\right]$

Where, ${ }^{M b}$ is the maximum bed capacity, $\mathrm{mg} ;{ }^{\mathrm{C}_{\mathrm{o}}}$ is the initial PAH concentration, $\mathrm{mg} \mathrm{l}^{-1}$;

$\mathrm{C}_{\mathrm{t}}$ is the PAH effluent concentration at ${ }^{t}$ time, min.; $V_{\text {tis }}$ the volume of ${ }^{t}$ time fraction, 1 .

Equilibrium PAH uptake /Adsorption capacity $\left(q_{e(\exp )}\right)$

The adsorption capacity of the single biomass or combinations was calculated by the following equation:

$q_{e(\exp )}=M b / m$

Where, ${ }^{q_{e(\exp )}}$ is equilibrium PAH uptake, mg $\mathrm{g}^{-1} ;{ }^{m}$ is the mass of biomass in the column, $\mathrm{g}$.

The total amount of PAH sent to the column $\left(\boldsymbol{M}_{\text {total }}\right)$

$M_{\text {total }}$ is calculated by the following equation:

$M_{\text {total }}=\frac{C_{0} Q t_{\text {total }}}{1000}$

Where, ${ }^{M_{\text {total }}}$ is the total amount of PAH sent to the column, $\mathrm{mg} ; C_{\circ}$ is initial $\mathrm{PAH}$ concentration, $\mathrm{mg} \mathrm{l}^{-1} ; \quad Q$ is volumetric flow rate, $\mathrm{ml} \mathrm{min}^{-1}$; ${ }_{\text {total }}$ is total flow time, $\mathrm{min}$.
Total percentage of PAH removal (\%)

Total \% removal is calculated by the following equation:

$\%$ Removal $=\frac{M b}{M_{\text {total }}} 100$

Where, ${ }^{M b}$ is the maximum bed capacity, mg; $M_{\text {total }}$ is total amount of PAH sent to the column, mg;

\section{Breakthrough point}

To determine the operation and the dynamic reaction of an adsorption column, the important characteristics needed to be considered are time for breakthrough appearance and the shape of the breakthrough curve. The loading behavior of contaminant to be adsorbed from solution in a fixed-bed is usually expressed in term of $\mathrm{C}_{t /} \mathrm{C}_{\alpha_{a}}$ ast a function of time or volume of the effluent for a given bed height, gives a breakthrough curve (Aksu and Gonen, 2004).

Here, the ratio of effluent PAH concentration $\left(\mathrm{C}_{\mathrm{t}}\right)$ and influent PAH concentration $\left({ }^{\mathrm{C}_{\alpha}}\right.$ ) was used for determining the breakthrough point. The time at which the ratio was near to 1.0 indicated the breakthrough point. The breakthrough point was calculated for 0.01 , $0.1,1$ and $10 \mathrm{mg} \mathrm{l}^{-1}$ for the same amount of both uncoated and coated pellets.

\section{Modeling of column bed adsorption}

The successful design of a column adsorption process requires prediction of the concentration-time profile or breakthrough curve for the effluent and the maximum adsorption capacity of an adsorbent under given set of operating conditions. In the present work, three kinetic models namely Thomas, Adams-Bohart and Yoon-Nelson 
were used to express the dynamic process of the column mode to use in evaluating the behavior, efficiency, and applicability of column for the large-scale operations. The data obtained from the column in continuous mode studies were used to calculate the maximum solid phase concentration or the saturation concentration of adsorbate on the adsorbent, and the adsorption rate constant corresponding to each kinetic model developed by people represent in the model name.

\section{Thomas model}

The Thomas model (Thomas, 1944) is one of the most general and widely used methods in column performance theory. Thomas model is the mass transfer model that assumes the adsorbing species drifts from the solution to the layer around the particle and diffuses through the liquid layer to the surface of the adsorbent. The linear form of Thomas model for continuous flow adsorption is:

$\ln \left(\frac{C_{0}}{C_{\mathrm{t}}}-1\right)=\frac{k_{\mathrm{TH}} q_{\mathrm{e}(\max )^{m}}}{Q}-k_{\mathrm{TH}} C_{0} t$

Where, ${ }^{C_{0}}$ is initial PAH concentration, $\mathrm{mg} \mathrm{l}^{-1}$; $C_{\mathrm{t}}$ is effluent $\mathrm{PAH}$ concentration, $\mathrm{mg} \mathrm{l}^{-1}$ at time $t_{;} q_{\mathrm{e}(\max )}$ is prediction maximum adsorption capacity, $\mathrm{mg} \mathrm{g}^{-1} ; Q$ is inlet flow rate, $\mathrm{ml} \min ^{-1} ;{ }^{m}$ is mass of adsorbent, $\mathrm{g} ;{ }^{t}$ is time, min.; and $k_{T H}$ is Thomas model constant, $\mathrm{ml} \mathrm{mg}{ }^{-1} \min ^{-1}$.

The two unknown parameters of Thomas equation i.e. ${ }^{k_{\mathrm{TH}} \text { and }} q_{\mathrm{e}(\max )}$ were determined from the slope and intercept of the plot of $\ln \left(\frac{C_{0}}{c_{\mathrm{t}}}-1\right)$ versus $^{t}$. The experimental $q_{\text {e(exp) }}$ was calculated as the adsorption capacity at the exhaustion time, ${ }^{t}$ which corresponds to, $\frac{c_{\mathrm{t}}}{c_{0}}=0.5$

\section{Adams-Bohart model}

Adams-Bohart model (Bohart and Adams, 1920 ) is based on the surface reaction theory which assumes that equilibrium is not instantaneous. This approach focused on the estimation of characteristic parameters such as saturation concentration $\left({ }^{N_{0}}\right)$ and kinetic constant $\left(k_{\mathrm{AB}}\right)$. The linear expression for Adams-Bohart model is the following:

$\ln \left(\frac{C_{\mathrm{t}}}{c_{\mathrm{0}}}\right)=k_{\mathrm{AB}} C_{0} t-\frac{k_{\mathrm{AB}} N_{0} Z}{U_{0}}$

Where, $C_{0}$ and $C_{\mathrm{t}}$ are influent and effluent $\mathrm{PAH}$ concentration, $\mathrm{mg} \mathrm{l}^{-1} ; k_{\mathrm{AB}}$ is kinetic constant, $\mathrm{ml} \mathrm{mg}^{-1} \min ^{-1} ; U_{0}$ is flow rate, $\mathrm{ml}$ $\min ^{-1} ;{ }^{Z}$ is bed depth of column, cm and $N_{0}$ is saturation concentration, $\mathrm{mg} \mathrm{l}^{-1}$.

The values of $N_{0}$ and $k_{\mathrm{AB}}$ were determined from the intercept and slope of the linear plot of $\ln \left(\frac{c_{t}}{c_{0}}\right)$ against time ${ }^{t}$ at a given bed height and flow rate.

\section{Yoon-Nelson model}

The Yoon-Nelson (Yoon and Nelson, 1984) model is less complicated than other models and requires no detailed data concerning the characteristics of adsorbate, type of adsorbent, and physical properties of the adsorption bed (Aksu and Gonen, 2004). The main aim of this model is to predict the time of column run before it's regeneration or replacement becomes necessary. Yoon-Nelson model is based on the assumption that the rate of decrease in the probability of adsorption for each adsorbate molecule is proportional to the probability of adsorbate adsorption and the 
probability of adsorbate breakthrough on the adsorbent. The linearized equation for a single component system is expressed as:

$\ln \left(\frac{c_{\mathrm{t}}}{c_{\mathrm{o}}-c_{\mathrm{t}}}\right)=k_{\mathrm{YN}} t-k_{\mathrm{YN}} \tau$

Where $C_{0}$ is the initial adsorbent species concentration, $\mathrm{mg} \mathrm{l}^{-1} ; C_{\mathrm{t}}$ is the effluent concentration, $\mathrm{mg} \mathrm{l}^{-1}$ at time ${ }^{t} ;{ }^{t}$ is the time, min.; ${ }^{\tau}$ is the time required for the $50 \%$ adsorbate breakthrough, min. and $k_{\mathrm{YN}}$ is the Yoon-Nelson rate constant, $\mathrm{min}^{-1}$.

The two unknown parameters of Yoon-Nelson equation, i.e., ${ }^{k_{\mathrm{YN}}}$ and ${ }^{\tau}$ were determined from slope and intercept of the plot of $\ln \left(\frac{c_{\mathrm{t}}}{c_{\mathrm{o}}-c_{\mathrm{t}}}\right)_{\text {versus }}{ }^{t}$. Based on Yoon-Nelson model, the amount of PAH being adsorbed in the column is half of the total PAH entering the column within $2 \tau$ period. For a given column $q_{\max }$ is calculated as:

$q_{\max }=\frac{\frac{1}{3} C_{0} \frac{Q}{1000} 2 \pi}{m}$

Where ${ }^{C_{0}}$ is the initial feed concentration, $\mathrm{mg}$ $1^{-1} ; Q$ is the flow rate, $\mathrm{ml} \min ^{-1}$ and ${ }^{m}$ is the total weight of adsorbent, g.

\section{Results and Discussion}

\section{Effect of initial pyrene concentration $\left(C_{0}\right)$ on adsorption}

Effect of initial PAH concentration was studied by conducting the experiment at 0.01 , $0.1,1$ and $10 \mathrm{mg} \mathrm{L}^{-1}$ while flow rate, bed height for both coated (P-(CS+AA)) and uncoated $(\mathrm{P})$ pellets were fixed at $120 \mathrm{ml} \mathrm{min}^{-}$ 1, $16 \mathrm{~cm}$. Experiments conducted at ambient temperature $\left(26^{0} \mathrm{C} \pm 2\right)$. The column parameters obtained from effect of initial Pyr concentration are given in the Table 1a.

With the increase in initial Pyr concentration, the obvious decrease in the percent removal for both types of pellets was observed. The pellets coated with trace amount of bio adsorbents has shown elevated removal efficiencies at each concentration over uncoated pellets.

The column bed capacity $(M b)$ was noticed to increase with increasing initial $\mathrm{Pyr}$ concentration (Fig. 1a and 1b) for both pellet types. However, at 10ppm after 105 minutes column become saturated hence, no more absorption occurred in both the pellets while for rest of the concentrations bed capacity is continuously increasing during the experiment period. Therefore, the maximum bed capacities at $10 \mathrm{ppm}$ for the two columns used uncoated and coated pellets were 46.31 and $51.46 \mu \mathrm{g}$ respectively.

The adsorption capacity $\left(q_{\mathrm{e}(\exp )}\right)$ was observed to increase with increasing initial $\mathrm{Pyr}$ concentration (Table 1a). The pellets coated with bio adsorbents have shown elevated adsorption capacities at each concentration over uncoated pellets.

The effect of influent Pyr concentration on the shape of the breakthrough curves is shown in Figure $2 \mathrm{a}$ and $2 \mathrm{~b}$. It is illustrated that the breakthrough time decreased with increasing influent Pyr concentration. At lower influent Pyrconcentrations, breakthrough curves were dispersed and during the experiment period breakthrough point not occurred as it reaches slowly. As influent concentration increased, slightly steeper breakthrough curves were obtained. These results demonstrate that the change of concentration gradient affects the saturation rate and breakthrough time (Goel et $a l ., 2005)$. This can be explained by the fact 
that with increase in Pyr concentration, higher Pyr molecules create a higher driving force for mass transfer resulting from a decreased adsorption zone. i.e., more adsorption sites were being covered as the Pyr concentration increases. Therefore, the column becomes saturated earlier because a fixed number of binding sites present in each column. However, due to ample amount of binding sites present in the column at lower concentrations, two types of pellets shown close adsorption capacity values while at higher concentration the values are significantly different.

\section{Effect of adsorbent mass ( $m$ ) on adsorption}

The effect of the mass of adsorbent on adsorption by varying the dose from $220 / 220.36$ to $440 / 440.73 \mathrm{~g}$ for $\mathrm{P} / \mathrm{P}(\mathrm{CS}+\mathrm{AA})$ in the column is shown in the Table $1 \mathrm{~b}$.

With the increase of $m$, the obvious increase in the \% removal for both types of pellets was observed. The $\mathrm{P}(\mathrm{CS}+\mathrm{AA})$ shown higher removal efficiencies at both adsorbent masses over P. As the adsorbent mass increased, Pyr solution had more time to contact with the adsorbent. This resulted in higher PAH removal. This resulted in lower Pyr concentration in the effluent.

Both $M b$ and $q_{\text {e(exp) }}$ were observed to increase with increasing adsorbent dose, $m$ (Table 1b), for both pellet types as shown in Figure 1c, at lower $m$, bed get saturated earlier (at $75 \mathrm{~min}$ and $90 \mathrm{~min}$ for $\mathrm{P}$ and $\mathrm{P}-(\mathrm{CS}+\mathrm{AA})$ respectively) while at higher $m$ the bed gets saturated later (at $105 \mathrm{~min}$ for both pellet types).

At higher adsorbent dose $(m)$, more sites were available for adsorption, and this resulted in higher PAH uptake. In the case of coated pellets bed received extra binding cites form chitosan and alginic acid, hence higher removal of PAH observed. From the Figure $2 \mathrm{c}$, it can be observed that the slope of the breakthrough curve decreased with increase in $m$, which resulted in a higher mass transfer zone. The breakthrough curve was slightly steeper at lower bed mass, and breakthrough point achieved at $90 \mathrm{~min}$. in the experiment that has used uncoated pellets.

\section{Effect of flow rate $(Q)$ on adsorption}

On varying the inlet flow rate from 90 to 120 $\mathrm{ml} \mathrm{min}^{-1}$, the obtained column parameters are listed in the Table 1c.

It shows the \% Pyr removal decreased with increase in flow rate. Higher adsorption $(M b)$ was observed at a lower flow rate, and the column got saturated at 105 min. time when using higher flow rate (Fig. 1d).

The adsorption capacity of the bed decreased with increase in flow rate (Table 1c). At higher flow rate, residence time of solute in the bed was less and the solute left the column before equilibrium was reached.

At different $Q$, the trend showing in Figure 1d was observed on breakthrough curve. It shows that faster breakthrough occurred at higher flow rate.

At lower flow rate, there was sufficient time for the PAH solution to get adsorbed on adsorbent. Higher Pyr removal occurred at lower flow rates for both Pellets. At higher flow rate, the breakthrough curve became steeper and shifted to origin. At lower flow rate, it will take more time for the bed to get saturated.

\section{Column kinetic study}

The column adsorption data were analyzed using three thermodynamic models viz. Thomas, Adams-Bohart and Yoon-Nelson. 
Fig.1a Pyr absorbed amount: the effect of influent concentration $(0.01,0.1 \mathrm{ppm})$ on Pyr adsorption by $\mathrm{P}$ and $\mathrm{P}-(\mathrm{CS}+\mathrm{AA})$ in the column $(Q=120 \mathrm{ml} / \mathrm{min}, m(\mathrm{P})=440 \mathrm{~g}$, $m(\mathrm{P}-\mathrm{CS}+\mathrm{AA})=440.73 \mathrm{~g})$

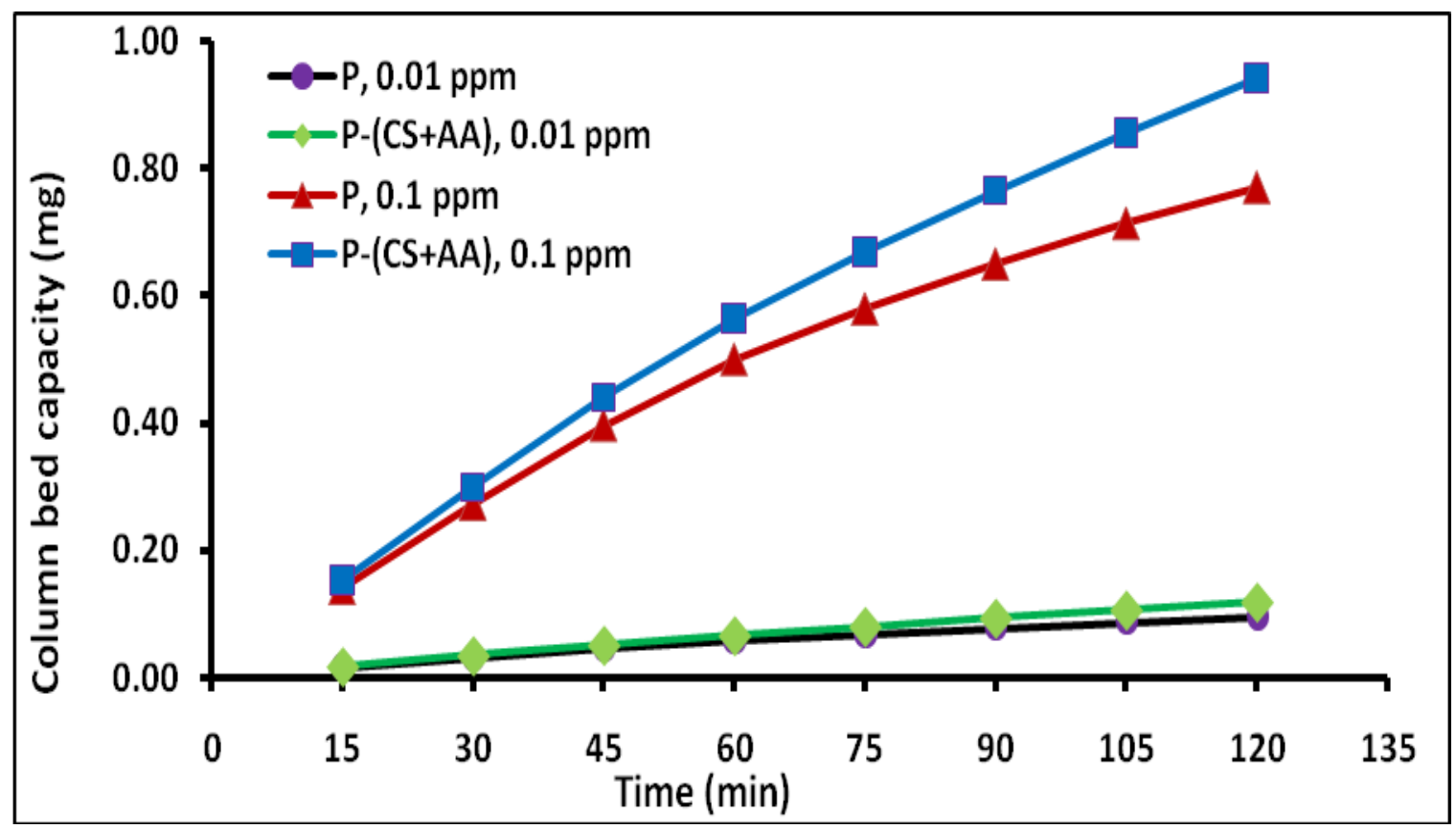

Fig.1b Pyr absorbed amount: the effect of influent concentration (1, $10 \mathrm{ppm})$ on Pyr adsorption by $\mathrm{P}$ and $\mathrm{P}-(\mathrm{CS}+\mathrm{AA})$ in the column $(Q=120 \mathrm{ml} / \mathrm{min}, m(\mathrm{P})=440 \mathrm{~g}, m(\mathrm{P}-\mathrm{CS}+\mathrm{AA})=440.73 \mathrm{~g})$

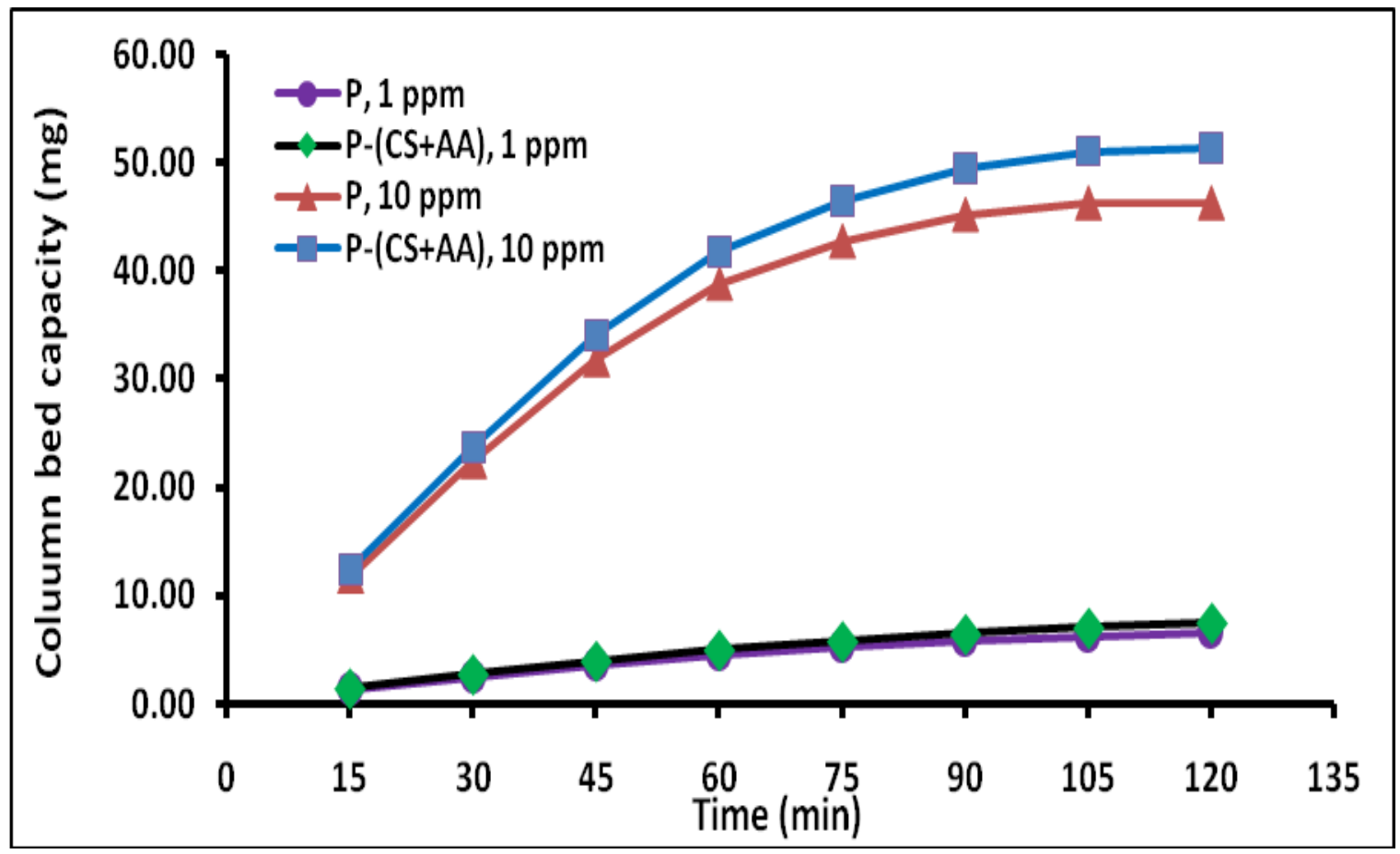


Fig.1c Pyr absorbed amount: the effect of adsorbent dose on Pyr adsorption by P and P-CS+AA in the column $\left(C_{0}=10 \mathrm{ppm}, Q=120 \mathrm{ml} / \mathrm{min}\right)$

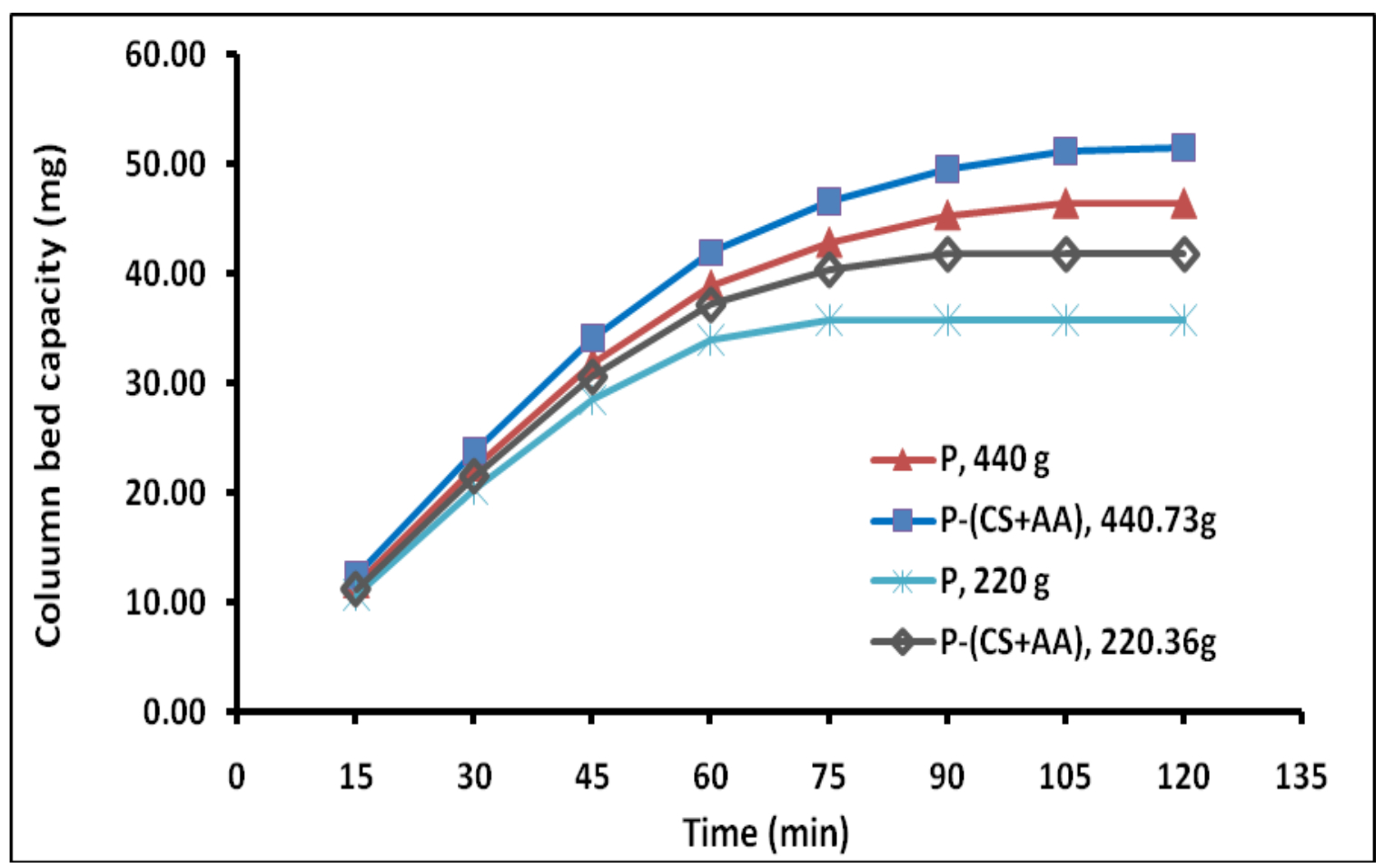

Fig.1d Pyr absorbed amount: the effect of flow rate on Pyr adsorption by $\mathrm{P}$ and P-CS+AA in the column $\left(C_{0}=10 \mathrm{ppm}, m(\mathrm{P})=440 \mathrm{~g}, m(\mathrm{P}-\mathrm{CS}+\mathrm{AA})=440.73 \mathrm{~g}\right)$

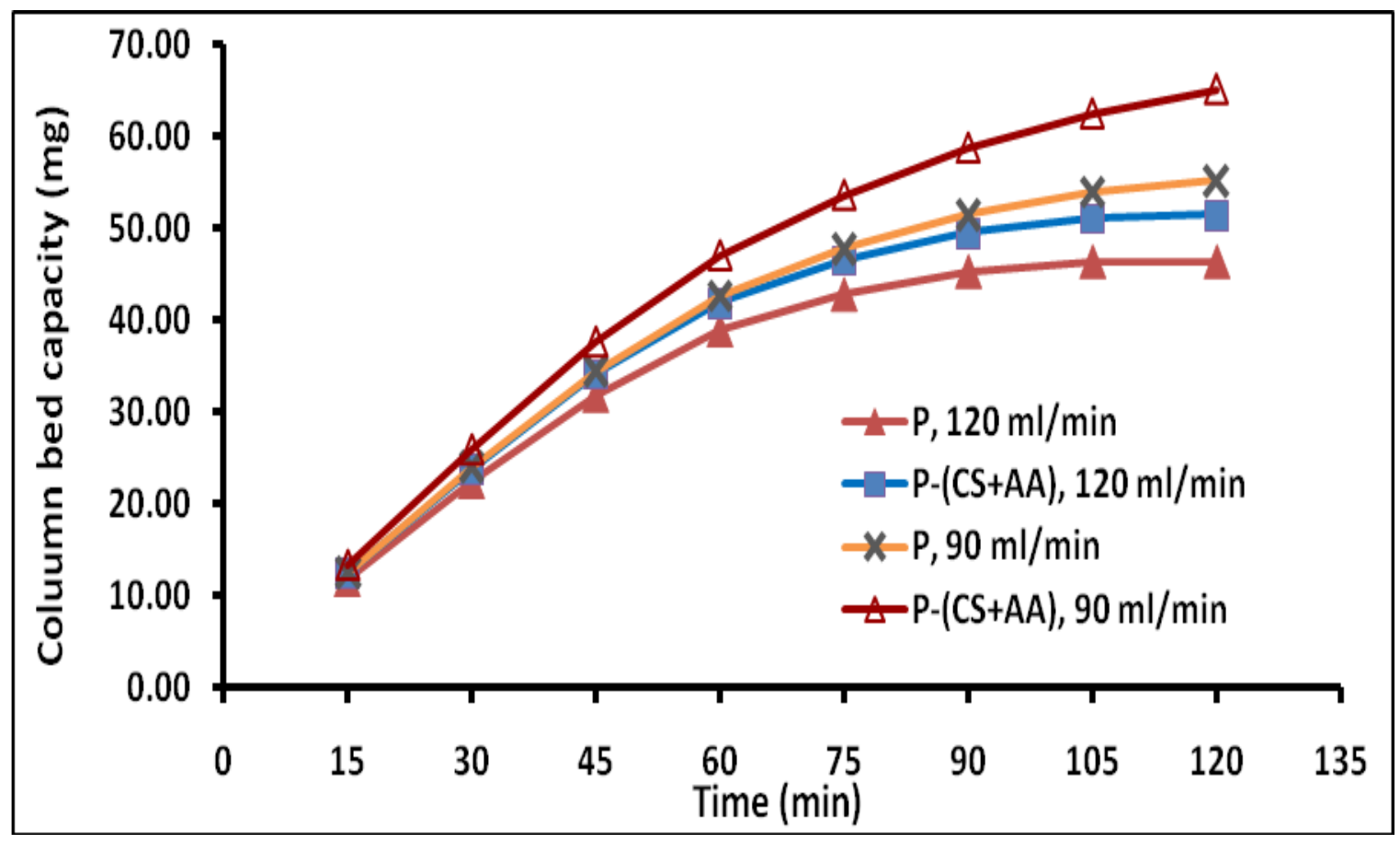


Fig.2a Breakthrough curves: the effect of influent concentration on Pyr adsorption by Pin the column $\left(Q=120 \mathrm{ml} \mathrm{min}^{-1}, m(\mathrm{P})=440 \mathrm{~g}\right)$

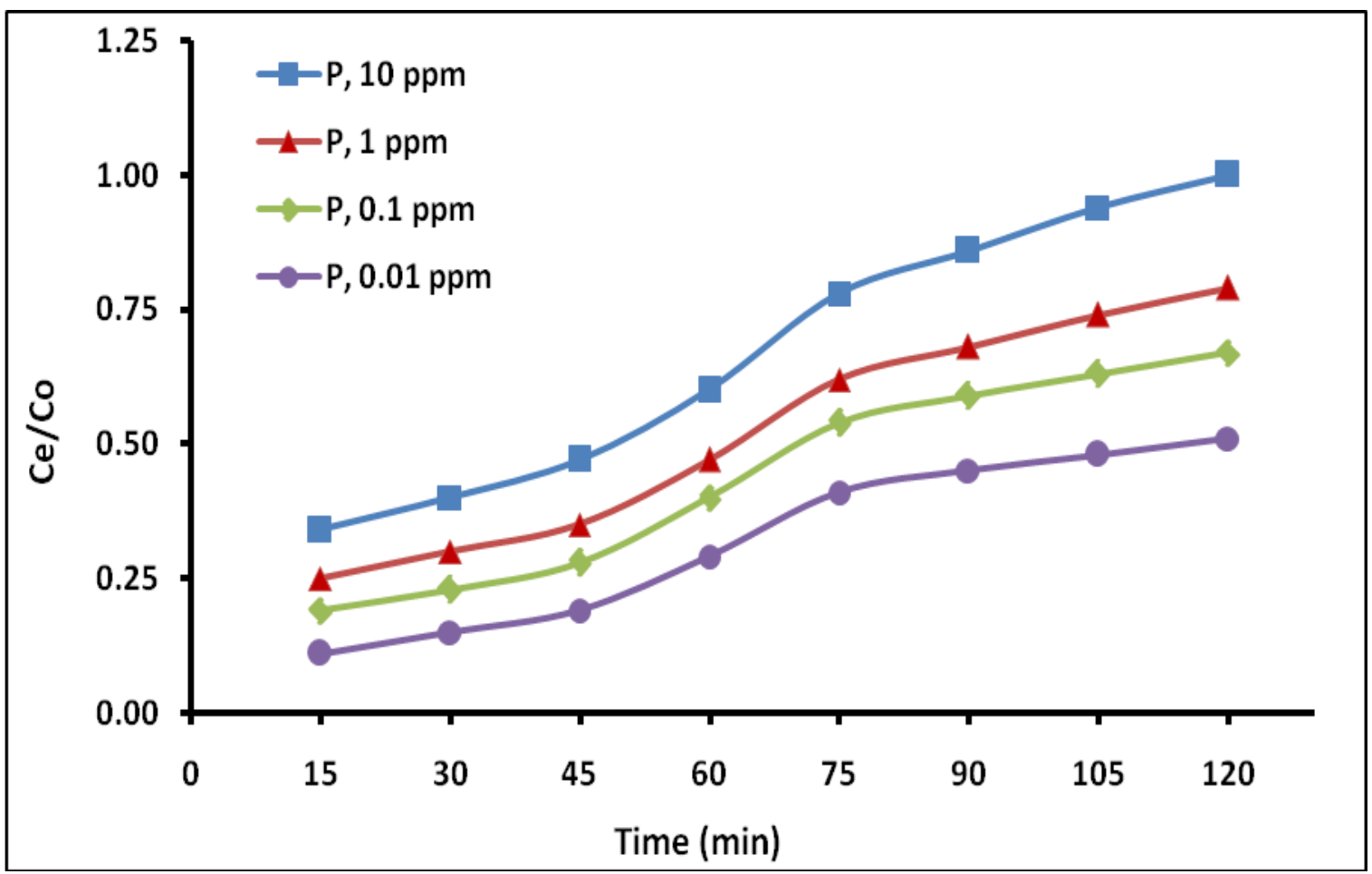

Fig.2b Breakthrough curves: the effect of influent concentration on Pyr adsorption by P-

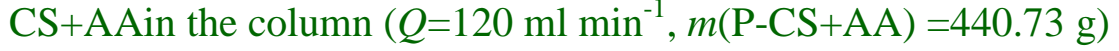

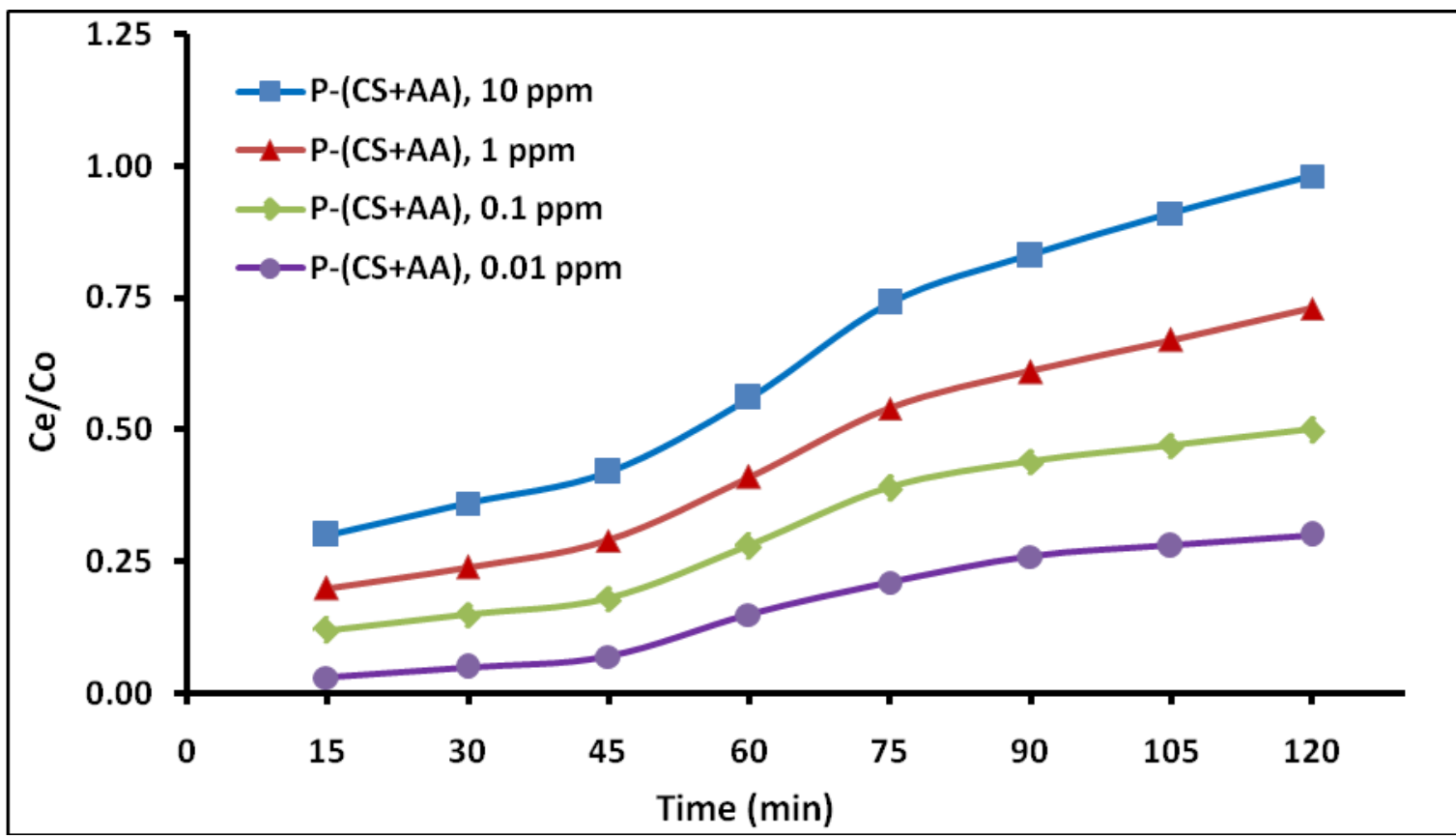

Fig.2c Breakthrough curves: the effect of mass of adsorbent on Pyr adsorption by P and P- 
(CS+AA) in the column $\left(C_{0}=10 \mathrm{ppm}, Q=120 \mathrm{ml} / \mathrm{min}\right)$

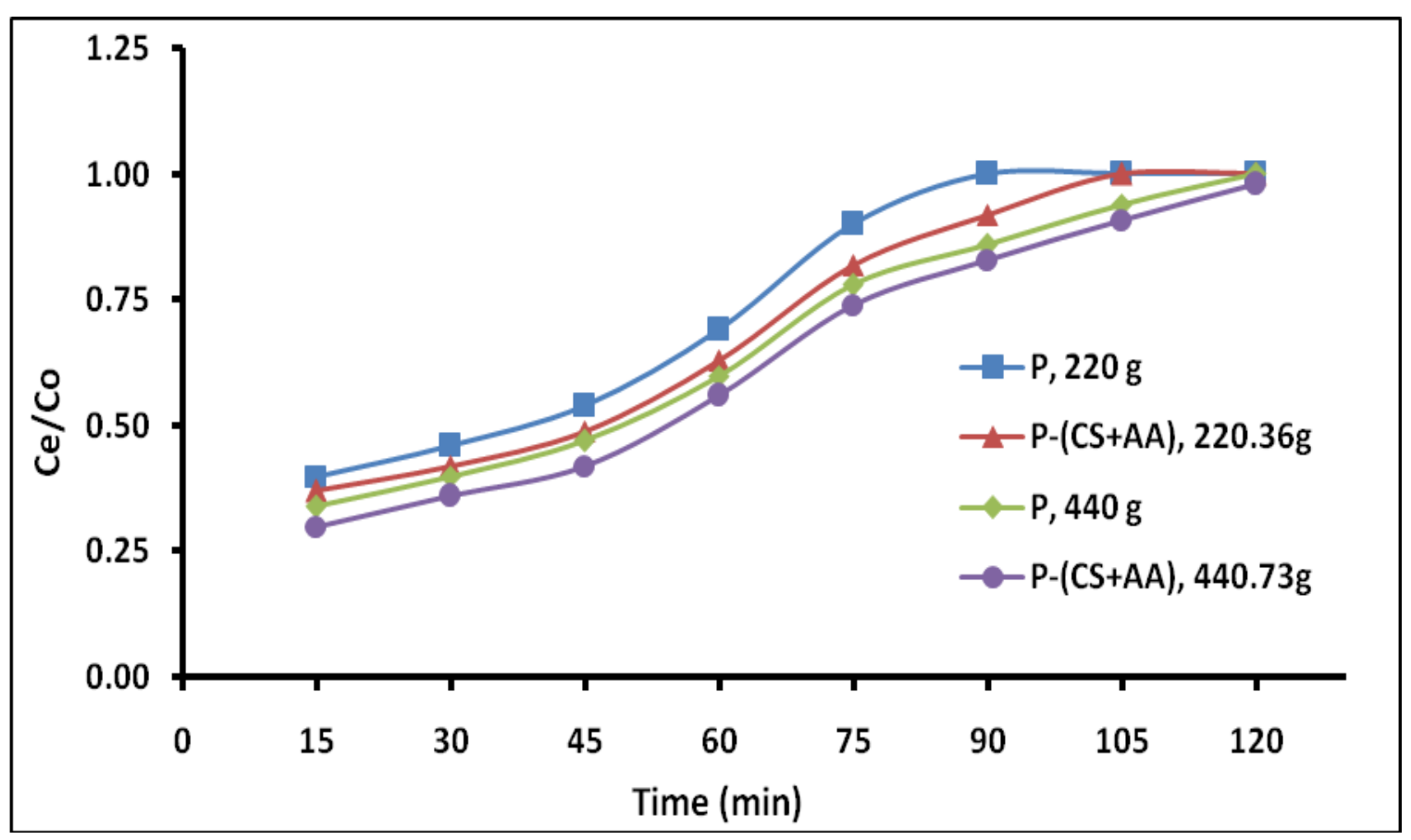

Fig.2d Breakthrough curves: the effect of flow rate on Pyr adsorption by P and P-CS+AA in the column $\left(C_{0}=10 \mathrm{ppm}, m(\mathrm{P})=440 \mathrm{~g}, m(\mathrm{P}-\mathrm{CS}+\mathrm{AA})=440.73 \mathrm{~g}\right)$

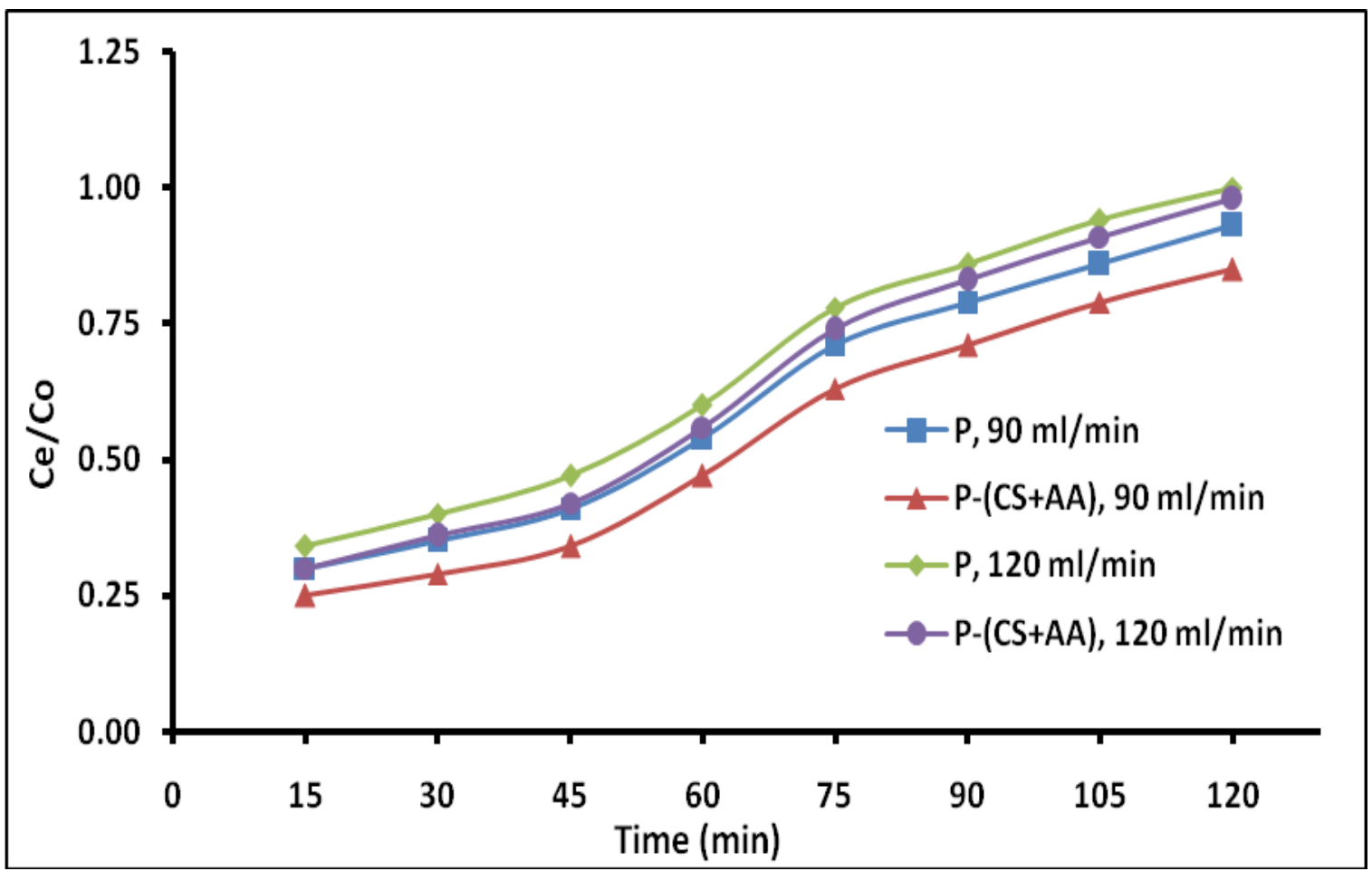

Table.1a Effect of initial pyrene concentration on adsorption by both P andP-CS+AA 


\begin{tabular}{|c|c|c|c|c|c|c|c|c|}
\hline \multirow{2}{*}{$\begin{array}{l}\text { Pyr Influent } \\
\text { Conc., Co } \\
\left(\mathrm{mg} \mathrm{l}^{-1}\right)\end{array}$} & \multirow{2}{*}{$\begin{array}{l}V_{\text {eff }} \\
(\mathrm{ml})\end{array}$} & \multirow[t]{2}{*}{$M_{\text {total }}(\mathbf{m g})$} & \multicolumn{3}{|c|}{$\mathbf{P}$} & \multicolumn{3}{|c|}{ P-CS+AA } \\
\hline & & & $\begin{array}{l}\mathrm{Mb} \\
(\mathrm{mg})\end{array}$ & $\begin{array}{l}q_{\text {e(exp) }}(\mathrm{mg} \\
\mathrm{g}-1)\end{array}$ & $\begin{array}{l}\% \text { Pyr } \\
\text { removal }\end{array}$ & $\begin{array}{l}\mathrm{Mb} \\
(\mathrm{mg})\end{array}$ & $\begin{array}{c}q_{\text {e(exp) }}(m g \\
\text { g-1) }\end{array}$ & $\begin{array}{l}\% \text { Pyr } \\
\text { removal }\end{array}$ \\
\hline 10 & 14400 & 141.28 & 46.31 & 0.1144 & 32.78 & 51.46 & 0.1295 & 36.42 \\
\hline 1 & 14400 & 14.28 & 6.59 & 0.0171 & 46.12 & 7.47 & 0.0201 & 52.31 \\
\hline 0.1 & 14400 & 1.43 & 0.77 & 0.0021 & 53.92 & 0.94 & 0.0030 & 65.99 \\
\hline 0.01 & 14400 & 0.14 & 0.10 & 0.0003 & 67.20 & 0.12 & 0.0005 & 82.61 \\
\hline
\end{tabular}

Table.1b Effect of adsorbent masson adsorption by both P andP-CS+AA

\begin{tabular}{|c|c|c|c|c|c|c|c|c|c|}
\hline $\begin{array}{c}\text { Adsorbent } \\
\text { mass, } \boldsymbol{m}(\mathbf{P}) /\end{array}$ & $\begin{array}{c}\boldsymbol{V}_{\text {eff }} \\
(\mathbf{m l})\end{array}$ & $\boldsymbol{M}_{\text {total }}(\mathbf{m g})$ & \multicolumn{3}{|c|}{$\mathbf{P}$} & \multicolumn{3}{|c|}{ P-CS+AA } \\
$\begin{array}{c}\boldsymbol{m}(\mathbf{P}- \\
\mathbf{C S}+\mathbf{A A})(\mathrm{g})\end{array}$ & & $\begin{array}{c}\mathrm{Mb} \\
(\mathrm{mg})\end{array}$ & $\begin{array}{c}q_{\text {e(exp) }}(\mathrm{mg} \\
\mathrm{g}-1)\end{array}$ & $\begin{array}{c}\% \text { Pyr } \\
\text { removal }\end{array}$ & $\begin{array}{c}\text { Mb } \\
(\mathrm{mg})\end{array}$ & $\begin{array}{c}q_{\text {e(exp) }}(\mathrm{mg} \\
\mathrm{g}-1)\end{array}$ & $\begin{array}{c}\% \text { Pyr } \\
\text { removal }\end{array}$ \\
\hline $\mathbf{4 4 0 / 4 4 0 . 7 3}$ & 14400 & 141.28 & 46.31 & 0.1144 & 32.78 & 51.46 & 0.1295 & 36.42 \\
\hline $\mathbf{2 2 0} / \mathbf{2 2 0 . 3 6}$ & 14400 & 141.28 & 35.66 & 0.0893 & 25.24 & 41.70 & 0.1045 & 29.51 \\
\hline
\end{tabular}

Table.1c Effect of flow rate on adsorption by both $\mathrm{P}$ andP-CS+AA

\begin{tabular}{|c|c|c|c|c|c|c|c|c|c|}
\hline $\begin{array}{c}\text { Flow rate, } \\
\boldsymbol{Q} \\
\left(\mathbf{m l} \mathbf{m i n}^{-1}\right)\end{array}$ & $\begin{array}{c}\boldsymbol{V}_{\text {eff }} \\
(\mathbf{m l})\end{array}$ & $\begin{array}{c}\boldsymbol{M}_{\text {total }}(\mathbf{m g} \\
\end{array}$ & \multicolumn{3}{|c|}{$\mathbf{P}$} & \multicolumn{3}{|c|}{ P-CS+AA } \\
\hline $\mathbf{1 2 0}$ & 14400 & 141.28 & 46.31 & 0.1144 & 32.78 & 51.46 & 0.1295 & 36.42 \\
\hline $\mathbf{9 0}$ & 10800 & 105.96 & 55.18 & 0.1362 & 52.08 & 65.12 & 0.1633 & 61.45 \\
\hline
\end{tabular}

Table.2a Thomas Model parameters using linear regression analysis under various operating conditions for Pyr adsorption by uncoated Pellets

\begin{tabular}{|c|c|c|c|c|c|c|}
\hline $\begin{array}{l}\text { Pyrene Influent } \\
\text { Conc., Co }\left(\mathrm{mg} \mathrm{l}^{-1}\right)\end{array}$ & $\begin{array}{l}\text { Flow rate, } \\
Q\left(\mathrm{ml} \mathrm{min}^{-}\right)\end{array}$ & $\begin{array}{l}\text { Adsorbent } \\
\text { mass, } m \\
\text { (g) }\end{array}$ & $\underset{\left(\mathbf{m g ~ g}^{-1}\right)}{q_{\text {(eep }}}$ & $k_{\mathrm{TH} .}\left(\mathrm{ml} \mathrm{mg}^{-1}\right)^{-1} \min ^{-}$ & $\begin{array}{c}q_{\mathrm{e}(\max )} \\
\left(\mathrm{mg} \mathrm{g}^{-1}\right)\end{array}$ & $\mathbf{R}^{2}$ \\
\hline 10 & 120 & 440 & 0.1144 & 0.0039 & 0.1105 & 0.9600 \\
\hline 1 & 120 & 440 & 0.0171 & 0.0257 & 0.0165 & 0.9842 \\
\hline 0.1 & 120 & 440 & 0.0021 & 0.2349 & 0.0021 & 0.9665 \\
\hline 0.01 & 120 & 440 & 0.0003 & 2.2151 & 0.0003 & 0.9501 \\
\hline 10 & 120 & 220 & 0.0893 & 0.0042 & 0.0871 & 0.8759 \\
\hline 10 & 90 & 440 & 0.1362 & 0.0034 & 0.1317 & 0.9785 \\
\hline
\end{tabular}

Table.2b Thomas Model parameters using linear regression analysis under various operating 
conditions for Pyr adsorption by P-CS+AA

\begin{tabular}{|c|c|c|c|c|c|c|}
\hline $\begin{array}{l}\text { Pyrene Influent } \\
\text { Conc., Co }\left(\mathrm{mg} \mathrm{I}^{-1}\right)\end{array}$ & $\begin{array}{l}\text { Flow rate, } Q \\
\left.(\mathrm{ml} \mathrm{min})^{-1}\right)\end{array}$ & $\begin{array}{l}\text { Adsorbent } \\
\text { mass, } m \text { (g) }\end{array}$ & $\underset{\left(\mathbf{m g ~ g}^{-1}\right)}{q_{\mathrm{e}(\exp )}}$ & $\begin{array}{c}k_{\mathrm{TH} .}\left(\mathrm{ml} \mathrm{mg}^{-1}\right. \\
\left.\min ^{-1}\right)\end{array}$ & $\begin{array}{c}q_{\mathrm{e}(\max )} \\
\left(\mathrm{mg} \mathrm{g}^{-1}\right)\end{array}$ & $\mathbf{R}^{2}$ \\
\hline 10 & 120 & 440.73 & 0.1295 & 0.0037 & 0.1246 & 0.9695 \\
\hline 1 & 120 & 440.73 & 0.0201 & 0.0251 & 0.0197 & 0.9860 \\
\hline 0.1 & 120 & 440.73 & 0.0030 & 0.2182 & 0.0029 & 0.9553 \\
\hline 0.01 & 120 & 440.73 & 0.0005 & 2.6926 & 0.0004 & 0.9313 \\
\hline 10 & 120 & 220.36 & 0.1045 & 0.0040 & 0.1007 & 0.9257 \\
\hline 10 & 90 & 440.73 & 0.1633 & 0.0029 & 0.1611 & 0.9849 \\
\hline
\end{tabular}

Table.3a Adams-Bohart Model parameters using linear regression analysis under various operating conditions for Pyr adsorption by Pellets

\begin{tabular}{|c|c|c|c|c|c|}
$\begin{array}{c}\text { Pyrene Influent } \\
\text { Conc., } \boldsymbol{C}_{\boldsymbol{o}}\left(\mathbf{m g ~ \mathbf { l } ^ { - 1 }}\right)\end{array}$ & $\begin{array}{c}\text { Flow rate, } \boldsymbol{Q} \\
\left(\mathbf{m l} \mathbf{m i n}^{-\mathbf{1}}\right)\end{array}$ & $\begin{array}{c}\text { Adsorbent } \\
\text { mass, } \boldsymbol{m}(\mathbf{g})\end{array}$ & $\begin{array}{c}\boldsymbol{k}_{\mathrm{AB}}\left(\mathbf{l} \mathbf{~ m g}^{-\mathbf{1}}\right. \\
\left.\mathbf{m i n}^{-\mathbf{1}}\right)\end{array}$ & $\begin{array}{c}\boldsymbol{N}_{\boldsymbol{o}}(\mathbf{m g ~ l} \\
\mathbf{1})\end{array}$ & $\mathbf{R}^{\mathbf{2}}$ \\
\hline $\mathbf{1 0}$ & 120 & 440 & 0.00123 & 7.69 & 0.9800 \\
\hline $\mathbf{1}$ & 120 & 440 & 0.01226 & 0.93 & 0.9577 \\
\hline $\mathbf{0 . 1}$ & 120 & 440 & 0.13575 & 0.04 & 0.9406 \\
\hline $\mathbf{0 . 0 1}$ & 120 & 440 & 1.57493 & 0.01 & 0.9287 \\
\hline $\mathbf{1 0}$ & 120 & 220 & 0.00137 & 6.38 & 0.9801 \\
\hline $\mathbf{1 0}$ & 90 & 440 & 0.00118 & 8.64 & 0.9654 \\
\hline
\end{tabular}

Table.3b Adams-Bohart Model parameters using linear regression analysis under various operating conditions for Pyr adsorption by P-CS+AA

\begin{tabular}{|c|c|c|c|c|c|}
\hline $\begin{array}{c}\text { Pyrene Influent } \\
\text { Conc., } \boldsymbol{C}_{\boldsymbol{0}}\left(\mathbf{m g ~ l}^{-\mathbf{1}}\right)\end{array}$ & $\begin{array}{c}\text { Flow rate, } \boldsymbol{Q} \\
\left(\mathbf{m l ~ m i n}^{-1}\right)\end{array}$ & $\begin{array}{c}\text { Adsorbent } \\
\text { mass, } \boldsymbol{m}(\mathbf{g})\end{array}$ & $\begin{array}{c}\boldsymbol{k}_{\mathrm{AB}}\left(\mathbf{l} \mathbf{~ m g}^{-\mathbf{1}}\right. \\
\left.\mathbf{m i n}^{-1}\right)\end{array}$ & $\begin{array}{c}\boldsymbol{N}_{\boldsymbol{0}}\left(\mathbf{m g} \mathbf{I}^{-}\right. \\
\mathbf{1})\end{array}$ & $\mathbf{R}^{\mathbf{2}}$ \\
\hline $\mathbf{1 0}$ & 120 & 441.5 & 0.00135 & 7.80 & 0.9789 \\
\hline $\mathbf{1}$ & 120 & 441.5 & 0.01381 & 0.96 & 0.9614 \\
\hline $\mathbf{0 . 1}$ & 120 & 441.5 & 0.15559 & 0.11 & 0.9385 \\
\hline $\mathbf{0 . 0 1}$ & 120 & 441.5 & 2.33699 & 0.01 & 0.9166 \\
\hline $\mathbf{1 0}$ & 120 & 220.75 & 0.00139 & 6.93 & 0.9751 \\
\hline $\mathbf{1 0}$ & 90 & 441.5 & 0.00130 & 9.06 & 0.9647 \\
\hline
\end{tabular}

Table.4a Yoon-Nelson Model parameters using linear regression analysis under various operating conditions for Pyr adsorption by Pellets

\begin{tabular}{|c|c|c|c|c|c|c|c|c|}
\hline $\begin{array}{l}\text { Pyr Influent } \\
\text { Conc., Co } \\
\left(\mathrm{mg} \mathrm{l}^{-1}\right)\end{array}$ & $\begin{array}{l}\text { Flow rate, } \\
Q\left(\begin{array}{c}\mathrm{ml} \mathrm{min}^{-} \\
1\end{array}\right)\end{array}$ & $\begin{array}{l}\text { Adsorbent } \\
\text { mass, } m \\
\text { (g) }\end{array}$ & $\begin{array}{c}\tau_{\text {exp }}(\mathrm{mi} \\
\mathbf{n})\end{array}$ & $\underset{\left(\mathbf{m g ~ g}^{-1}\right)}{q_{\text {e(exp) }}}$ & $\begin{array}{c}k_{\mathrm{YN}} \\
\left(\mathrm{min}^{-1}\right)\end{array}$ & $\tau(\min )$ & $\underset{\left(\mathrm{mg} \mathrm{g}^{-1}\right)}{q_{\mathrm{e}(\max )}}$ & $\mathbf{R}^{2}$ \\
\hline 10 & 120 & 440 & 42.76 & 0.1144 & 0.0383 & 41.11 & 0.1105 & 0.9600 \\
\hline 1 & 120 & 440 & 63.19 & 0.0171 & 0.0247 & 62.88 & 0.0165 & 0.9842 \\
\hline 0.1 & 120 & 440 & 78.60 & 0.0021 & 0.0225 & 79.85 & 0.0021 & 0.9665 \\
\hline 0.01 & 120 & 440 & 107.37 & 0.0003 & 0.0218 & 106.35 & 0.0003 & 0.9501 \\
\hline 10 & 120 & 220 & 33.39 & 0.0893 & 0.0411 & 32.39 & 0.0869 & 0.8759 \\
\hline 10 & 90 & 440 & 50.91 & 0.1362 & 0.0333 & 49.00 & 0.1315 & 0.9785 \\
\hline
\end{tabular}

Table.4b Yoon-Nelson Model parameters using linear regression analysis under various 
operating conditions for Pyrene adsorption by P-CS+AA

\begin{tabular}{|c|c|c|c|c|c|c|c|c|}
\hline $\begin{array}{c}\text { Influent } \\
\text { Conc., Co } \\
\left(\mathrm{mg} \mathrm{l}^{-1}\right)\end{array}$ & $\begin{array}{l}\text { Flow rate, } \\
Q\left(\mathrm{ml} \mathrm{min}^{1}\right)\end{array}$ & $\begin{array}{l}\text { Adsorbent } \\
\text { mass, } m \\
\text { (g) }\end{array}$ & $\begin{array}{c}\tau_{\exp }(\mathbf{m i} \\
\mathbf{n})\end{array}$ & $\underset{\left(\mathbf{m g ~ g}^{-1}\right)}{q_{\text {e(exp) }}}$ & $\begin{array}{c}k_{\mathrm{YN}} \\
\left(\mathrm{min}^{-1}\right)\end{array}$ & $\tau(\min )$ & $\begin{array}{c}q_{\mathrm{e}(\max )} \\
\left(\mathrm{mg} \mathrm{g}^{-1}\right)\end{array}$ & $\mathbf{R}^{2}$ \\
\hline 10 & 120 & 440.73 & 48.47 & 0.1295 & 0.0361 & 46.43 & 0.1246 & 0.9695 \\
\hline 1 & 120 & 440.73 & 74.39 & 0.0201 & 0.0242 & 75.26 & 0.0197 & 0.9860 \\
\hline 0.1 & 120 & 440.73 & 110.73 & 0.0030 & 0.0209 & 109.36 & 0.0029 & 0.9553 \\
\hline 0.01 & 120 & 440.73 & 177.24 & 0.0005 & 0.0265 & 137.89 & 0.0004 & 0.9313 \\
\hline 10 & 120 & 220.36 & 39.10 & 0.1045 & 0.0399 & 37.52 & 0.1007 & 0.9257 \\
\hline 10 & 90 & 440.73 & 61.13 & 0.1633 & 0.0288 & 60.03 & 0.1611 & 0.9849 \\
\hline
\end{tabular}

\section{Thomas model}

The experimental column data were fitted with Thomas model to investigate the breakthrough behavior of PAH adsorption on column. The linearized form of Thomas model (equation 7) was used to estimate the kinetic coefficient ${ }^{k_{T H}}$ and maximum adsorption capacity $q_{\max }$ for various operating conditions are summarized in Table $2 \mathrm{a}$ and $2 \mathrm{~b}$ for $\mathrm{P}$ and $\mathrm{P}-(\mathrm{CS}+\mathrm{AA})$ respectively.

In the tables, it indicates that the experimental maximum adsorption capacities and maximum adsorption capacities obtained from Thomas model are almost same. So, the experimental data are in good agreement with the theoretical results. The values of $\mathrm{R}^{2}$ found to be in the range of 0.876 to 0.984 (uncoated pellets) and 0.926 to 0.986 (coated pellets) which shows the good fitting of Thomas model to the experimental data with high correlation coefficients.

It can be observed that with increase in concentration of $\mathrm{Pyr},{ }^{q_{\max }}$ increased and $k_{T H}$ decreased. This is because, with increase in concentration, the driving force for adsorption increased. The driving force for adsorption is the concentration difference between the Pyr on the adsorbent and the Pyr in the solution (Aksu and Gonen, 2004, Han, 2006). Thus the high driving force due to the higher $\mathrm{Pyr}$ concentration resulted in better column performance.

In the case of bioadsorbents coated pellets used column, the value of $\mathrm{q}_{\max }$ is higher than that of in uncoated pellets for each corresponding concentration while corresponding $k_{T H}$ values are lesser after coating. This is because bio adsorbents giving more reactive sites to attach by Pyr molecules in pellets.

With an increase in flow rate, the maximum adsorption capacity decreased, and coefficient $k_{T H}$ increased. This can be attributed to the residence time of solute in the bed was less.

The value of $q_{\max }$ increased with increase in adsorbent mass and corresponding $k_{T H}$ values decreased as at higher adsorbent mass, more reactive sites are available. The Thomas model is suitable for adsorption processes where the external and internal diffusions will not be the limiting step (Aksu and Gonen, 2004).

\section{Adams-Bohart model}

This approach focused on the estimation of saturation concentration, $N_{0}$, and AdamsBohart kinetic constant, ${ }^{k_{\mathrm{AB}}}$ from the model by linear regression analysis (equation 8 ). For all breakthrough curves, respective values of $N_{0}$ and $k_{\mathrm{AB}_{\text {were }}}$ calculated and are 
presented in Table $3 \mathrm{a}$ and $3 \mathrm{~b}$ together with the correlation coefficients, $\mathrm{R}^{2}$.

The values of ${ }^{k_{\mathrm{AB}}}$ decreased, and $N_{0}$ increased with initial Pyr concentration. The results show that the saturation concentration $N_{0}$ decreased with increase in flow rate while corresponding coefficients $k_{\mathrm{AB}}$ increased. The decrease in $N_{0}$ is because of the lower residence time of solute in the column. As the adsorbent mass increased, the $N_{0}$ increased while ${ }^{k_{\mathrm{AB}}}$ values decreased. This showed that the overall system kinetics was dominated by external mass transfer in the initial part of adsorption in the column (Aksu and Gonen, 2004). The $R^{2}$ values were $R^{2}>0.929$ and $\mathrm{R}^{2}>0.917$ for uncoated and coated pellets respectively which shows the good linearity and the good agreement of experiment data with predicted data with high correlation coefficients.

\section{Yoon-Nelson model}

The breakthrough behavior of Pyr adsorption on the column was also investigated by applying Yoon-Nelson model. The YoonNelson rate constant, ${ }^{k_{Y N}}$ and time required for $50 \%$ breakthrough, ${ }^{\tau}$ were determined using Yoon-Nelson model by linear regression analysis (equation 9). The calculated parameters of Yoon-Nelson model at different experimental conditions for uncoated and coated pellet types are tabulated in Table $4 \mathrm{a}$ and $4 \mathrm{~b}$ respectively. With an increase in influent concentration, the values of ${ }^{k_{\text {yn }}}$ increased and values of ${ }^{\tau}$ decreased. Also, the calculated maximum adsorption capacity, ${ }_{\mathrm{B}(\max )}$ increased with the increase in $\mathrm{Pyr}$ concentration. At higher $\mathrm{Pyr}$ concentration, the driving forcefor adsorption increased. This resulted in lesser time for the bed to get saturated. When flow rate increased, the time required for $50 \%$ breakthrough decreased. This can be attributed to the lesser residence time of solute in the column at higher $Q$. For both pellets, the Yoon-Nelson rate constant increased with increase in flow rate.

When increasing adsorbent dose, the time required for $50 \%$ breakthrough increased because more adsorption sites were available hence, breakthrough time decreased (Han, 2009). The data in Table $3 a$ and $3 b$ also indicate that values of ${ }^{\tau}$ are similar to the experimental results.

High values of correlation coefficients $\left(\mathrm{R}^{2}\right)$, similar experimental and calculated maximum adsorption capacity $\left(q_{\mathrm{e}}\right)$ and times for $50 \%$ breakthrough $^{(\tau)}$ indicate that Yoon-Nelson model fitted well to the experimental data.

On the basis of the experimental results of this investigation, the following conclusions can be drawn:

The newly designed fixed bed column device consisting of reusable pellets could be effectively used as a low-cost approach to remove Pyrene from contaminated water.

The adsorption of Pyrene was dependent on the flow rate, influent Pyr. Concentration and adsorbent dose.

The experimental data were found to be in good agreement with calculated results at all experimental conditions for Thomas, AdamsBohart and Yoon-Nelson models.

Overall, the study provides a novel design of a column bed and baseline information for the efficient removal of PAH in general and pyrene in particular from the water.

\section{Acknowledgements}


Authors are thankful to The Director ICARCentral Institute of Fisheries Education and Head and staff of Aquatic Environment and Health Management Division, ICAR-CIFE for the cooperation and support. The financial support to the first author by Indian Council for Cultural Relations (ICCR) in the form of scholarship is gratefully acknowledged. The first author also acknowledges the INASP, UK for the useful online training on research writing under Author AID.

\section{References}

Abdel-Shafy, H.I., and Mansour, M.S., 2016. A review on polycyclic aromatic hydrocarbons: source, environmental impact, the effect on human health and remediation. Egyptian Journal of Petroleum, 25(1), pp.107-123.

Aksu, Z. 2005. Application of biosorption for the removal of organic pollutants: a review, Process biochemistry, 40, pp. 997-1026.

Aksu, Z. and Gönen, F., 2004.Biosorption of phenol by immobilized activated sludge in a continuous packed bed: prediction of breakthrough curves. Process biochemistry, 39(5), pp.599-613.

Bohart, G., Adams, E. Q., 1920. Some aspects of the behaviour of charcoal with respect to chlorine. J. Am. Chem. Soc. 42, 523-544.

Goel, J., Kadirvelu, K., Rajagopal, C. and Garg, V.K., 2005. Removal of lead (II) by adsorption using treated granular activated carbon: batch and column studies. Journal of hazardous materials, 125(1), pp. 211-220.

Han, R., Wang, Y., Zhao, X., Wang, Y., Fuling, X., Cheng, J. and Tang, M., 2009. Adsorption of methylene blue by phoenix tree leaf powder in a fixed-bed column: experiments and prediction of breakthrough curves. Journal of Desalination 245, pp.284-297.
Han, R., Zhang, J., Zou, W., Xiao, H., Shi, J. and Liu, H., 2006. Biosorption of copper (II) and lead (II) from aqueous solution by chaff in a fixed-bed column. Journal of Hazardous materials, 133(1), pp.262-268.

Hu, C.Y., Lo, S.L., Kuan, W.H. and Lee, Y.D., 2005.Removal of fluoride from semiconductor wastewater by electrocoagulation-flotation. Water research, 39(5), pp.895-901.

Lamichhane, S., Bal Krishna, K.C. and Sarukkalige, R., 2016. Polycyclic aromatic hydrocarbons (PAHs) removal by sorption: A review. Chemosphere, 148, pp.336-353.

Manual for Monitoring Oil and Dissolved/Dispersed Petroleum Hydrocarbons in Marine Waters and on Beaches. UNESCO publication,1984. identifier. uri: http://hdl.handle.net/ 11329/88, description (accessed on 17/01/2018)

Mohapatra, D., Mishra, D., Mishra, S.P., Chaudhury, G.R. and Das, R.P., 2004. Use of oxide minerals to abate fluoride from water. Journal of colloid and interface science, 275(2), pp.355-359.

Ndiaye, P.I., Moulin, P., Dominguez, L., Millet, J.C. and Charbit, F., 2005.Removal of fluoride from electronic industrial effluent by RO membrane separation. Desalination, 173(1), pp.25-32.

Parthasarathy, N., Buffle, J. and Haerdi, W., 1986. Study of interaction of polymeric aluminium hydroxide with fluoride. Canadian journal of chemistry, 64(1), pp.24-29.

Phillips, D.H., 1999. Polycyclic aromatic hydrocarbons in the diet. Mutation Research/Genetic Toxicology and Environmental Mutagenesis, 443(1), pp.139-147.

Ruixia, L., Jinlong, G. and Hongxiao, T., 2002.Adsorption of fluoride, phosphate, 
and arsenate ions on a new type of ion exchange fiber. Journal of colloid and interface science, 248(2), pp.268-274.

Simons, R., 1993. Trace element removal from ash dam waters by nanofiltration and diffusion dialysis. Desalination, 89(3), pp.325-341.

Thomas, H. C., 1944. Heterogeneous ion exchange in a flowing system. J. Am. Chem. Soc. 66, 1664-1666.

USEPA, 1992. Plastic pellets in the aquatic environment: Sources and recommendations. Environmental Protection Agency: Oceans and Coastal Protection Division Final Report 842-B92-010. Washington, DC.

Yoon, Y. H., Nelson, J. H., 1984. Application of gas adsorption kinetics. I. A theoretical model for respirator cartridge service time. Am. Ind. Hyg. Assoc. J. 45, 509-516.

Zedeck, M.S., 1980. Polycyclic aromatic hydrocarbons: a review. Journal of environmental pathology and toxicology, 3(5-6), p.537.

Zhang, C., Wu, L., Cai, D., Zhang, C., Wang, N., Zhang, J. and Wu, Z., 2013. Adsorption of polycyclic aromatic hydrocarbons (fluoranthene and anthracenemethanol) by functional graphene oxide and removal by $\mathrm{pH}$ and temperature-sensitive coagulation. $A C S$ applied materials and interfaces, 5(11), pp.4783-4790.

\section{How to cite this article:}

Anusha D.L. Wickramasinghe, S.P. Shukla, A.K. Balange, K. Pani Prasad and Sanath Kumar. 2018. A Novel Fixed Column Bed Device for Removal of Polycyclic Aromatic Hydrocarbon (Pyrene) from Water: Performance Evaluation and Thermodynamic Modelling. Int.J.Curr.Microbiol.App.Sci. 7(03): 94-111. doi: https://doi.org/10.20546/ijcmas.2018.703.011 